\title{
Organizational Ecology: No Darwinian Evolution After All. A Rejoinder to Lemos
}

Philosophy of the Social Sciences 40(3) 504-512

(C) The Author(s) 2010 Reprints and permission: http://www. sagepub.com/journalsPermissions.nav DOI: I0.1 |77/0048393/09348866 http://pos.sagepub.com

(SAGE

\author{
Markus Scholz' and \\ Thomas A.C. Reydon'
}

\begin{abstract}
In a recent article we argued that organizational ecology is not a Darwinian research program. John Lemos criticized our argumentation on various counts. Here we reply to some of Lemos's criticisms.
\end{abstract}

\section{Keywords}

Darwinism, evolution, organization theory, organizational ecology, organizational systematics, population ecology of organizations

\section{Introduction}

In a recent article in this journal, we argued that organizational ecology cannot be thought of as a research program that is grounded in Darwinian evolutionary theory (Reydon and Scholz 2009). Our main argument was that organizational ecology theory lacks an evolutionary mechanism that can be identified as the principal cause of organizational diversity. In our view, the "evolution" of organizational populations by means of selection (which is put forward in organizational ecology as the mechanism that produces the

Received I July 2009

'Center for Philosophy and Ethics of Science (ZEWW), Leibniz Universität Hannover, Hannover, Germany

\section{Corresponding Author:}

Thomas A.C. Reydon, Center for Philosophy and Ethics of Science (ZEWW), Im Moore 2I, Leibniz Universität Hannover, Hannover, 30167, Germany

E-mail: reydon@ww.uni-hannover.de 
diversity of organizational forms that we find in the world) is not evolution in the biological sense, as organizational "populations" lack crucial properties required to function as evolutionary units.

Lemos (2009) recently criticized our argumentation on various counts. While Lemos agreed that there are disanalogies between biological evolution and organizational "evolution," he defended organizational ecology as a Darwinian research program, claiming that our interpretation of the organizational ecology program "is not sufficiently charitable in its understanding of the Darwinian nature of organizational ecology" (Lemos 2009, 12). We are grateful for Lemos's criticisms, as these provide us with an opportunity to clarify some central points of our argument further.

\section{Discussion with Lemos}

Lemos is correct in stating that we do not endorse a charitable interpretation of the idea of "Darwinism" in organizational ecology. We believe that from the perspective of philosophy of science, calling organizational ecology a Darwinian program, using "Darwinian" in a suitably loose sense, would be severely misleading. We explicated our reasons in our article and will not repeat them here (Reydon and Scholz, 2009, footnote 19). In fact, Lemos's text illustrates some misunderstandings. Lemos (2009, 1-2; emphasis added) explicated the Darwinian nature of organizational ecology as follows:

Organizational ecologists try to understand the growth of this diversity among organizations as the result of a struggle for survival among organizations with different traits, such that those with traits that favor them in the competition to survive continue to exist. Additionally, changes in organizational structures occur over time and the changes that are favorable tend to get reproduced in future years.

This quotation reveals two problems.

First, the mere survival of individual organizations with better traits and demise of organizations with worse traits does not constitute evolution of the sort that occurs in the biological realm. Biological evolution, after all, involves differential reproduction, not the mere survival of "better" organisms. In brief, organisms with better traits tend to have more offspring than organisms with worse traits, because their better traits allow them to live longer (engage in more reproductive cycles), attract more partners, etc. Precisely because better adapted organisms have more descendants - that 
have about the same level of adaptedness as their parents - than less welladapted ones, the population as a whole evolves toward a level of better adaptation. (This is why Herbert Spencer's slogan "survival of the fittest" is such a bad representation of Darwinian evolution: biological evolution does not consist in the survival of the best, but in more reproductive success for the better adapted as compared to the less well off.)

Second, Lemos's claim that favorable changes tend to be reproduced in future years is vague, as "reproduction" comes in various forms. As Lemos $(2009,464)$ explains, "Organizational ecology is basically the application of meme theory in the organizational context." Interestingly, none of the main authors in organizational ecology (Hannan, Freeman, McKelvey, Aldrich, Polós, Carroll) actually refer to meme theory in their writings. But if Lemos is right, the reproduction of favorable traits is not reproduction in the relevant sense: the simple spreading of "traits" from one entity to another does not constitute heredity. If one catches a flu virus from another person while traveling on the subway and consequently begins to exhibit the same behavior as that person (sneezing, sweating, etc.), this is not an instance of hereditary transmission of this behavioral trait between generations, resulting in gradual adaptation of the human population. (Indeed, Dawkins [1976, 206-07], the founder of meme theory, compared the spreading of memes through the human population to the spreading of viruses.) What reproduces are the memes themselves and what may evolve (in the biological sense) as a consequence is the population of memes, not the population of human beings. Similarly, if organizational ecology is the application of meme theory in the organizational domain, it would be concerned with the differential reproduction of free-floating ideas, comps (brief for "competences" or "competence elements"), etc. and the evolution of populations of ideas, comps, etc. - not with the evolution of populations of organizations! Moreover, its biological basis would be shaky, as meme theory is still highly controversial and does not constitute a part of the Darwinian orthodoxy in biology.

This brings us to the central issue in Lemos's criticism: the nature of organizational "populations" as compared to biological populations. Here, Lemos takes us to task on two counts. First, he disagrees with us that defining organizational "populations" as sets prevents them from being real entities that take part in evolutionary processes. Second, he disagrees with our claim that organizational "populations" do not have what it takes (i.e., sufficient levels of internal cohesion, closure, and isolation from other populations) to allow for processes close to biological evolution to occur.

We argued (Reydon and Scholz, 2009, section 4.1) that it is a mistake to define organizational populations typologically—as sets of organizations with 
a shared form-because this does not allow for the variation between the members of a population that is required for evolution to occur. Lemos finds this argument problematic and argues that defining organizational populations in terms of shared form can allow for significant variation. To illustrate his point he provides a concrete example:

... moving away from organizations for a moment, consider the population of motorized vehicles. There is a common form among these objects in virtue of which we call them all "motorized vehicles" but there is still tremendous variation among them-variation that can allow for evolution over time. There is even significant variation in the subcategories within this general heading, for instance not all motorcycles are the same. It may be that we see differences in the different forms of motorcycles today because certain kinds of motorcycles - dirt bikes - are more suited for use in certain environments than othersroad bikes. (Lemos, 2009, 468)

Of course there may be variations between the members of a typologically defined population, such as the one in Lemos's example, and such variation may be considerable. But we disagree with Lemos that such variation may be significant from an evolutionary perspective. In typologically defined populations, there can only be variation between the members with respect to properties that do not define the population - but there cannot be variation with respect to properties that define the population. Using Lemos's example: surely, there is much variation between motorized vehicles in various properties, but not in the property of being a motorized vehicle. Therefore, the "population" of motorized vehicles cannot be a subject to open-ended evolution: once vehicles emerge in the population that are not motorized or objects emerge that are not even vehicles, they automatically must be discounted as members of the population as they do not meet the definition of the population. The population thus can only evolve within the limits of being a population of motorized vehicles (if it can be said to be able to evolve at all). Similarly, the "population" of Italian restaurants can come to include new types of Italian restaurants, but it cannot evolve to become a "population" of, say, insurance companies. Wholly novel types of organizations cannot come into being as a consequence of gradual descent with modification from existing types!

The crucial point is that for biological populations this is fundamentally different. Biological evolution can in principle cause any organismal trait to disappear from a population or to change without the consequence that 
organisms lacking a trait that previously was widespread in a population must be discounted as members of the population. Hull (1978, 341; emphasis added) expressed this particularity of biological evolution thus:

The relevant organismal units in evolution are not sets of organisms defined in terms of structural similarity but lineages formed by the imperfect copying processes of reproduction. Organisms can belong to the same lineage even though they are structurally different from other organisms in that lineage. What is more, continued changes in structure can take place indefinitely. If evolution is to occur, not only can such indefinite structural variation take place but also it must.

When a biological population evolves, this can involve the coming into being of a new variation on an already existing basic form (which could also happen in the sort of population that Lemos considers) or the coming into being of an entirely novel organismal form. The latter (basically the origin of new biodiversity) consists in the movement of the population toward a new organismal form in the space of possible forms - something that cannot happen if the population is defined by a particular organismal form.

The point, then, is that defining populations in terms of structural similarities cannot allow for evolutionarily significant variation in populations. Typologically defined populations can change to a limited extent and new varieties of existing basic forms can come into being, but no entirely novel forms can come into being in the population. Once an entirely novel form comes into being, it falls outside the population, so the population has not evolved as an entity. That is, the origin of entirely novel forms cannot be understood in terms of the population undergoing a Darwinian evolutionary process, but must be understood in different terms. The problems with defining biological populations typologically have been extensively discussed among biologists and philosophers of biology since Mayr's 1959 essay on the opposition between "population thinking" and "typological thinking" (reprinted in Mayr [1976]) and at present no biologist would define populations typologically.

In our earlier article (Reydon and Scholz, 2009), we illustrated the mismatch between the organizational and biological notions of population by means of the notions of cohesion, closure, and isolation. We argued that to be able to partake in evolutionary processes a population must be sufficiently internally cohesive (meaning that traits must be passed on between generations within the same population, such that offspring largely resemble their parents), and sufficiently closed and isolated from other populations 
(meaning that traits/genetic material must largely remain within the population, without too much influx of new traits from other populations). The latter requirement expresses the biological idea that every population "has its own devices (called isolating mechanisms) to protect it from harmful gene flow from other gene pools" (Mayr 1963, 17).

Lemos $(2009,468-469)$ criticizes the validity of our cohesion and closure/ isolation requirements by considering an example involving fast-food restaurants. While fast-food restaurants used to have limited menus with few healthy items, today the variation in their menus is much larger and many more healthy items are included. Lemos suggests:

We might think of the original move to a more diverse and healthier menu as a mutation (albeit not a random one, as found in biological evolution, because it is an intentionally chosen strategy made by corporate executives) that aids in the competition for profits. . . The characteristic trait of a healthier and more diverse menu spread in the population because it was favorable. The end result is a transformed fast-food industry. And the transformation can be seen as the result of a favorable mutation spreading within the population of fast-food restaurants because of its adaptive advantage. Now, all of this is not just like Darwinian evolution but it comes pretty darn close. So, why shouldn't the organizational ecologists think of themselves as providing a kind of Darwinian account of the evolution of new organizational forms? (Lemos, 2009, 468-469; emphasis added)

Yes, this process prima facie looks like Darwinian evolution and yes, it can be explained by a "kind of" Darwinian account if one's usage of terminology is sufficiently loose, but it is not Darwinian evolution in the strict, biological sense of this notion. The example can indeed be seen as a case in which a new trait (a healthier menu) originated, spread to other members of the "population" and stabilized because members that did not come to exhibit this trait were selected against. But this by itself does not constitute Darwinian evolution.

First of all, there is no heredity in the example: the healthy-menu trait spread as a virus (as memes do) and not from generation to generation. Once the trait arose (i.e., was thought of by the manager of a chain or a restaurant), it infected both older and younger restaurants. While in biology (notwithstanding the occurrence of horizontal gene transfer), traits spread from the first generation to the second to the third ... to the nth, getting modified on the way, in Lemos's example the trait immediately spreads over all generations. It might even be modified by the manager of another restaurant 
and subsequently reinfect the restaurant where it first occurred! Because of the easiness with which such traits spread, if the "population" of fast-food restaurants is not sufficiently isolated from other "populations" of organizations, the new trait may be quickly displaced by a different trait flowing into the "population" from the outside, and so on for every new trait, giving no trait a chance of becoming fixated.

In addition, heredity in biology involves the transmission of much genetic material from ancestors to their descendants, so that descendants will resemble their ancestors in many respects, not just in a single trait. That is, while memes are transmitted separately, in biological reproduction genetic material is transmitted in large packages. In addition, organisms in a population interact with each other in various ways and are held together in the population by way of various mechanisms, such as reproduction, gene flow, social interactions, division of labor, mutual protection, intra- and interpopulation competition for mates and resources. In this way, the differential reproductive success of the organisms in generation $\mathrm{n}$ determines the composition of generation $n+1$ of the same population. This is what we mean by the requirement that populations should be sufficiently cohesive.

Third, irrespective of the preceding points, Lemos's example still cannot be understood as the evolution of a population in the Darwinian sense. That all restaurants changed to a healthier menu was made possible by the fact that individual restaurants already had the possibility of changes their menus in various ways. Biologists call this "phenotypic plasticity," the capability of organisms to change some traits in responses to environmental changes. In the same way as phenotypic plasticity allows organisms to change back to their old state if need be, so can restaurants change back from healthy menus to less healthy menus if consumer preferences change. This is not evolution, because it is individual organizations that change- the population is not the unit of change (the population changes only in a derivative sense, i.e., it changes only in that the properties of its members change). Biological evolution consists therein that organisms with less advantageous properties have less offspring than organisms with more favorable ones, such that the population changes as later generations have a different composition than earlier generations-here, it is the population that changes, not individual organisms. Without this change of populations as populations, there is no evolution.

\section{Conclusion}

Lemos asks, "What is so troubling about labeling something as a Darwinian theory, if it has some significant similarities to Darwinism while also containing some significant differences" (Lemos, 2009, 474) Well, nothing is 
wrong with calling a theory or research program "Darwinian" if there are significant similarities with Darwinian evolutionary theory and if these similarities far outweigh the differences. But in the case of organizational ecology we cannot see these similarities. The "populations" of organizations simply do not have what it takes to operate as entities in process of evolution. In biology, the term "evolution" has a very specific technical meaning and talk of "evolution" in organizational ecology does not involve this precise meaning.

Lemos $(2009,474)$ himself seems to recognize the existence of important differences between organizational ecology and biological evolution:

... changes in organizational form are often the result of intentional decision making on the part of organizational leaders who try to make profitable changes. In contrast, Darwinian evolution is the consequence of random mutation and random environmental changes. Furthermore, since the intentional decision making of organizational leadership often explains changes in organizational forms, there no longer seems to be much need for the Darwinian natural selective explanation of the origins of different organizational forms.

We agree with Lemos on this point, but while he only concludes that Darwinian explanations in organizational studies might be an "unnecessary extravagance", 2009, 474, we see more severe epistemological problems (Reydon and Scholz, 2009) as well as ethical and normative problems which result from a view of managers as powerless agents and organizations that are helpless in their struggle for existence (for a more extensive debate of the normative problems of organizational ecology, see Scholz and Reydon [2008a] and [2008b]).

\section{Declaration of Conflicting Interests}

The authors declared no potential conflicts of interests with respect to the authorship and/or publication of this article.

\section{Funding}

The authors received no financial support for the research and/or authorship of this article.

\section{References}

Dawkins, R. 1976. The selfish gene. New York: Oxford University Press. Hull, D. L. 1978. A matter of individuality. Philosophy of Science 45:335-60. 
Lemos, J. 2009. In defense of organizational evolution. A reply to Reydon and Scholz. Philosophy of the Social Sciences 39: 463-474.

Mayr, E. 1963. Populations, species, and evolution. Cambridge, MA: Harvard University Press.

Mayr, E. 1976. Evolution and the diversity of life. Cambridge, MA: Harvard University Press.

Reydon, T. A. C., and M. Scholz. 2009. Why organizational ecology is not a Darwinian research program. Philosophy of the Social Sciences 39: 408-439.

Scholz, M., and T. A. C. Reydon. 2008a. The population ecology programme in organization studies: Problems caused by unwarranted theory transfer. Philosophy of Management 6:39-51.

Scholz, M., and T. A. C. Reydon. 2008b. Wie praktische Probleme aus ungerechtfertigter Theorieübertragung hervorgehen können: Eine Fallstudie des populationsökologischen Ansatzes in der Organisationstheorie. In Betriebswirtschaftslehre und Unternehmensethik, ed. A. G. Scherer and M. Patzer, 125-43. Wiesbaden: Gabler.

\section{Bios}

Markus Scholz is a PhD student and teaching assistant at the Center for Philosophy and Ethics of Science (ZEWW), Leibniz University of Hannover. In addition, he teaches business ethics at the University of Applied Sciences and Arts of Hannover. His dissertation is concerned with the influence of theories from business studies on management practice and explores the foundations for business ethics. At present, he is temporarily at the London School of Economics and Political Sciences.

Thomas Reydon is DFG research fellow at the Center for Philosophy and Ethics of Science (ZEWW), Leibniz University of Hannover, where he is working on a research project on the topic of explanatory generalizations and natural kinds in the special sciences. His main areas of research are the philosophy of biology and the philosophy of social science. He is co-editor of Current Themes in Theoretical Biology: A Dutch Perspective (Springer, 2005) and associate editor of the journal Acta Biotheoretica. 